Int. J. Electrochem. Sci., 15 (2020) 12080 - 12102

\title{
Theoretical Investigation of Molecular Properties of 5-benzyl-6- methyl pyridazine-3-one and 5-benzyl-6-methyl pyridazine-3- thione and their Potentials for Corrosion Inhibition for Steel
}

\author{
Ubong Eduok \\ College of Engineering, University of Saskatchewan, 57 Campus Drive, Saskatoon, S7N 5A9, \\ Saskatchewan, Canada. \\ E-mail: ubong.eduok@usask.ca
}

doi: $10.20964 / 2020.12 .83$

Received: 18 August 2020 / Accepted: 12 October 2020 / Published: 31 October 2020

The present study theoretically investigates the molecular properties of two pyridazine derivatives (5benzyl-6-methyl pyridazine-3-one, PO and 5-benzyl-6-methyl pyridazine-3-thione, PS) using quantum chemical technique (Parameterization Method 3). It is also an attempt to offer a non-experimental account while justifying the respective contributions of PO and PS molcules as corrosion inhibitors visà-vis their adsorption on corroding steel substrates. These molecular level computations were conducted using semi-empirical molecular orbital (MO) technique in vacuo and $0 \mathrm{~K}$ for spatial molecular structures of pyridazines molecules with full geometry optimization. This was accomplished using the popular Polar-Ribiere algorithm with a convergence set of $0.1 \mathrm{kcal} /(\hat{\mathrm{A}}$ mol $) \mathrm{RMS}$ gradient. Also computed and discussed are the differences in molecular energies ( $E_{\text {HOMO }}$ and $\left.E_{\text {LUMO }}\right)$, Mulliken interatomic charge, dipole moments, bond lengths and angles, refractivity, polarizability and partition coefficients of both compounds. The obtained theoretical results align with previously reported experimental corrosion behaviours of both compounds. Corrosion inhibition was attributed to the formation of inhibitor layers on steel surface and this further reduced steel corrosion due to electronic activities involving $\pi$ electron donation via HOMO orbitals of these pyridazines to the empty $3 \mathrm{~d}$-orbitals of iron substrate. The compute magnitudes of $E_{\text {binding }}$ obtained from molecular dynamic (MD) simulations revealed a strong Fe-surface interaction for PS compared to PO.

Keywords: Semi-empirical method; Parameterization Method 3; Pyridazines; Corrosion; Corrosion inhibition; Energy gap

\section{$\underline{\text { FULL TEXT }}$}

(C) 2020 The Authors. Published by ESG (www.electrochemsci.org). This article is an open access article distributed under the terms and conditions of the Creative Commons Attribution license (http://creativecommons.org/licenses/by/4.0/). 